\title{
ESTABLECIMIENTO IN VITRO DE LOROCO (Fernaldia pandurata Woodson) ${ }^{1}$
}

\author{
Karla María Quintanilla-Moreno ${ }^{2}$
}

\begin{abstract}
RESUMEN
Establecimiento in vitro de loroco (Fernaldia pandurata Woodson). Se cultivaron meristemos apicales del brote de plantas de loroco en el laboratorio de Biotecnología del Centro Nacional de Tecnología Agropecuaria y Forestal (CENTA) en los meses de agosto de 2002 a abril 2003. Dichos explantes se establecieron en un medio basal de Murashige y Skoog, solidificado con Phytagel ( 2 g/l) suplementado con diferentes concentraciones de ácido naftalenacético (ANA) y ácido bencilaminopurina (BAP) en dosis comprendidas entre $0,5 \mathrm{mg} / 1$ y $1,0 \mathrm{mg} / \mathrm{l}$; con el objetivo de producir material vegetativo a través del cultivo in vitro para la propagación masiva de plantas de calidad genética y fitosanitaria, y la conservación y distribución de germoplasma vegetal. El pH fue ajustado a 5,7. Los explantes se sembraron en tubos de ensayo con $25 \mathrm{ml}$ de medio de cultivo estéril, estos fueron colocados a luz con intensidad de 1.500 lux. La temperatura de la cámara de crecimiento fue de $28+/-2{ }^{\circ} \mathrm{C}$. Se evaluaron nueve tratamientos con un diseño factorial $3^{2}$ completamente aleatorizado con diez observaciones cada uno. Además se realizaron pruebas de deshidratación de callos para la regeneración de plántulas; con cambios a medios frescos cada 28 días para un total de cuatro subcultivos en un lapso de cinco meses. Los resultados obtenidos indicaron la formación de brotes a los 15 días, en los tratamientos suplementados con $0,5 \mathrm{mg} / 1$ y $1,0 \mathrm{mg} / \mathrm{l}$ de BAP respectivamente, pero el tratamiento con 1,0 mg/l de BAP resultó ser más eficiente, con una mejor elongación y cantidad de tallos. Las restantes combinaciones de las concentraciones de ANA y BAP, solo favorecieron la formación de callos friables, existiendo diferencia significativa entre ellos.
\end{abstract}

Palabras clave: Micropropagación, in vitro, reguladores de crecimiento, loroco, meristemo.

\begin{abstract}
Establishment in vitro of loroco (Fernaldia pandurata Woodson). Apical meristems of loroco shoot plants were grown into basal medium of Murashige and Skoog, this medium was solidified with phytagel $(2 \mathrm{~g} / \mathrm{l})$ and supplemented with different concentrations of naphtalenacetic acid and bencylaminopurine acid in range of 0,5 and $1,0 \mathrm{mg} / \mathrm{l}$; with the objective of producing the vegetative material through the plant tissue culture in the massive propagation of genetic and sanitary plant quality, conservation and distribution of germoplasm. The $\mathrm{pH}$ was 5.7 , the explants were placed in test tubes containing $25 \mathrm{ml}$ of sterile culture medium, the tubes were placed under 1500 lux. The temperature of the growth chamber was $28+/-2^{\circ} \mathrm{C}$. Nine treatments were evaluated as a factorial complete random design, with ten repetitions each. Some dehydration tests of calluses were conducted for the regeneration of plants by changing to regular climate every 28 days having a total of four sub-cultivations in a lapse of five months. The results indicated that shoots form in fifteen days, and concentrations of 0,5 and $1,0 \mathrm{mg} / 1$ of BAP promote shoot development; the last one was most effective in stimulating elongation. Other combinations of ANA and BAP concentrations only promote friable callus formation and significant differences between them exist.
\end{abstract}

Key words: Micro-propagation, in vitro, plant grow regulatores, loroco, meristem.

\footnotetext{
1 Recibido: 25 de setiembre, 2004. Aceptado: 19 de marzo, 2007. Tesis de graduación (Licenciatura en Biología). Presentado en la L Reunión Anual del PCCMCA en El Salvador, América Central. 19-23 de abril, 2004.

2 Laboratorio de Biotecnología, Centro Nacional de Tecnología Agropecuaria y Forestal (CENTA-MAG), Kilómetro 33 1/2, carretera a Santa Ana, La Libertad, El Salvador, C.A. Apartado postal 885. Tel. (503) 23020273. Correo electrónico: karlimary@gmail.com
} 


\section{INTRODUCCIÓN}

El loroco (Fernaldia pandurata Woodson) es una planta que da sus primeras flores a los tres meses de plantada; soporta muy bien el estrés hídrico, pocos patógenos y plagas son capaces de atacarla y, además, se vende a buenos precios. Crece en toda América Central y algunas partes de México, sin embargo, solo en el Salvador se usa para consumo humano (Rivera 2001).

El loroco es una planta herbácea tipo liana que produce flores formando racimos con un promedio de 30 flores, el fruto es un folículo alargado con un promedio de 60 semillas, sus hojas oblongas elípticas (Osorio 1994). La planta posee dos alcaloides en sus raíces: la Lorocina y la Loroquina; las cuales tienen principios activos en la presión arterial y además el rizoma posee un fuerte olor oleáceo que es tóxico (Damas 1984).

Flores (1978) explica que en El Salvador esta planta solo aparece registrada taxonómicamente por Calderón (1941), quien la enlista como Urechites karwinskii Muller; atribuyéndole a Padilla, el reporte y distribución para los departamentos de San Salvador y Ahuchapán. Pero en 1932 se le reporta como Fernaldia pandurata Woodson, donde se le clasifica dentro de la familia Apocynaceae.

El loroco es una planta silvestre que crece asociada a la flora salvadoreña; a través del tiempo la población ha colectado sus flores para usarlas en diferentes platos típicos Navarro (1992) (Figura 1).

No existen en el país variedades híbridas, pero que hay por lo menos de cinco a ocho variedades que difieren en cuanto a características y adaptación. La forma y tamaño de las hojas es una marcada diferenciada, así como los colores de las flores, las cuales varían entre blancas cremosas y blancas amarillentas Orellana (1987).

El loroco es un cultivo no tradicional, que representa una buena alternativa para generar ingresos. Dicho cultivo no había tenido importancia en cuanto a su valor comercial y nutritivo, aunque algunos agricultores lo explotan en forma tradicional debido a la resistencia de esta planta, lo que le permite crecer

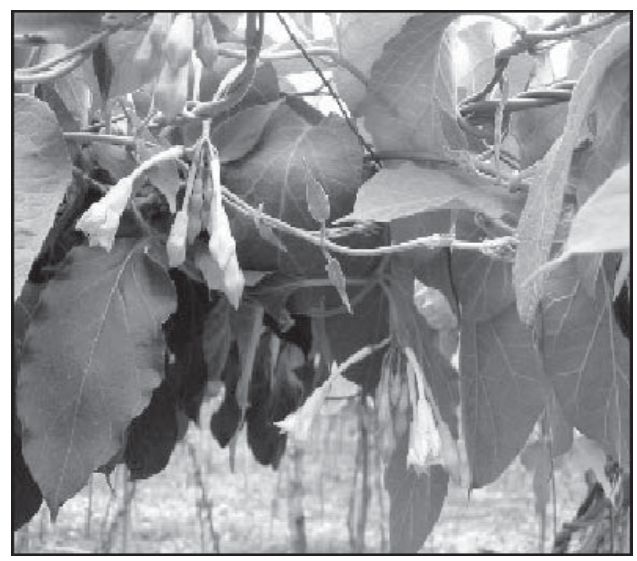

Figura 1. Estructura externa de la planta de loroco (Fernaldia pandurata Woodson).

rústicamente aprovechando sus flores y racimos tiernos (Argueta 1999).

Las políticas del sector agropecuario se orientan a la diversificación agrícola de El Salvador y a la promoción de exportación de cultivos no tradicionales, dentro de éstos, el cultivo de loroco representa una nueva alternativa que genera ingresos; solventa gran parte del problema económico de los agricultores.

En El Salvador, la producción de loroco resulta rentable, a pesar de que no existe suficiente material disponible para que el agricultor lo siembre; sin embargo, esta rentabilidad depende del nivel de tecnología usado para su producción, del área sembrada, las características ecológicas de la zona donde se produce y la fertilidad del suelo, entre otras. Además, el ciclo vegetativo de esta planta depende de la forma como se reproduzca: si se reproduce asexualmente (a través de rizomas y esquejes), florece a los seis o siete meses, pero si es reproducida por semilla (la cual se obtiene de los frutos maduros), la producción de flores se inicia entre los ocho y diez meses (ISTA 1985).

Dependiendo de la técnica de propagación que se utilice, se garantiza una floración precoz y exitosa. Dentro de las desventajas que se presentan con la propagación sexual se encuentra la viabilidad de la semilla para su germinación, además de la variabilidad genética; responsable de producir materiales heterogéneos (Osorio et al. 2002). 
La propagación asexual debe realizarse con material vegetativo proveniente de plantas fisiológicamente maduras; esto limita su reproducción; además, se debe tomar en cuenta que la cantidad de plantas propagadas por esta vía no logra abastecer el mercado local (Quintanilla 2003). Por ello, se trata de implementar la técnica de cultivo in vitro de tejidos vegetales de loroco; con esta técnica es posible producir suficiente material para garantizar y aumentar su producción todo el año. Esta herramienta resulta útil para propagar masivamente plantas de calidad genética y fitosanitaria, además de conservar y distribuir el germoplasma vegetal.

El cultivo de tejidos vegetales (pueden utilizarse diferentes partes de la planta) abarca un grupo de técnicas que consisten en el cultivo bajo condiciones asépticas, aislando fragmentos de tejidos u órganos de una planta completa para promoverlos a crecer en un medio ambiente apropiado, que permita expresar su capacidad morfogenética (López 1990).

Como parte de las investigaciones en el campo de la biotecnología, las técnicas de propagación de tejidos in vitro surge para contribuir al mejoramiento de especies de importancia alimenticia, agrícola o medicinal (FAO 1995).

Debido a la gran necesidad de asegurar una producción óptima de loroco durante todo el año, y producir plantas fisiológicamente sanas y libres de cualquier patógeno, para satisfacer la demanda nacional e internacional de dicho producto, se presenta la alternativa de micropropagación in vitro a partir de meristemos apicales del brote. Esta alternativa asegura producción de grandes cantidades de plantas, en corto tiempo y menor costo.

Las técnicas simples de cultivo de tejidos o micropropagación, están produciendo abundante material con sanidad controlada, libre de virus, hongos o bacterias reduciendo los gastos de protección del cultivo y aumentando su productividad.

La técnica consiste en clonar tejidos vegetales en forma aséptica y en medios artificiales. Este proceso ha servido para multiplicar determinadas variedades de diferentes plantas en forma masiva, y libre de patógenos (FAO 1995).
El explante es la parte de un tejido o de un órgano que se aísla del resto de la planta para ser cultivado. En el caso de especies propagadas vegetativamente, los brotes jóvenes y los ápices meristematicos han sido generalmente la fuente de los explantes. El tamaño del explante no tiene, aparentemente, mayor influencia, solo en el caso de pretender la obtención de plantas libres de virus, los meristemas sin primordios foliares tienen una alta probabilidad de diferenciar plantas libres de estos patógenos.

El explante de meristemo es fácilmente obtenido de los brotes en el estado vegetativo de crecimiento activo. Los meristemos terminales muestran mejores respuestas in vitro, que otros tomados de la posición lateral (Vasil y Torpe 1994).

El meristemo es un tejido compuesto por células que se dividen rápidamente y constituye el punto activo de crecimiento, una vez aislado se desarrolla en el medio de cultivo de una manera genéticamente estable, reduciendo el nivel de infección virótica en el tejido, conduciendo el desarrollo de plántulas (Espinoza et al. 1985). Del mismo modo reviste especial interés debido a su creciente utilización en la propagación, morfogénesis y mejoramiento genético (López 1990).

El ácido benzilaminopurina (BAP) es un compuesto sintético muy activo, es el que más se utiliza, ya que se encuentra disponible fácilmente a un menor costo. Se ha comprobado que es necesario para el crecimiento de tejidos separados de médula de tabaco. El BAP se utiliza en concentraciones entre 0,1 a 1 mg/l (CIAT 1991). En los medios de cultivo in vitro se incorporan citoquininas para promover la división celular y la inducción de yemas adventicias en callos y órganos. Además, se usan para la proliferación de tallos axilares por la ruptura de la dominancia apical (Narender y Kutty 1994).

Las auxinas se relacionan con la elongación, tropismo, dominancia apical, abscisión, enraizamiento y otros. En cultivo in vitro las auxinas son utilizadas principalmente para la diferenciación de raíces y la inducción de callos. El ácido indolbutiríco y el ácido naftalenacético son usados frecuentemente para enraizamiento (Narender y Kutty 1994). 
Hurtado y Merino (1987) manifiestan que un callo puede formar brotes, raíces, embriones, o simplemente continuar proliferando callo; esto depende de la orientación de las cantidades relativas de auxinas y citoquininas suministradas. Por lo que se recomienda enfocar investigaciones futuras en la optimización de concentraciones adecuadas de reguladores de crecimiento, tanto para citoquininas como para auxinas, esto permitiría una formación adecuada de plántulas de loroco vía callogénesis.

El presente trabajo tuvo por objetivo establecer material vegetativo de loroco a través de la técnica de cultivo in vitro de meristemos; y determinar la concentración óptima de reguladores de crecimiento capaces de inducir a las plántulas de esta especie a crecer.

\section{MATERIALES Y MÉTODOS}

\section{Ubicación y descripción del área de estudio}

La investigación se desarrolló en los meses comprendidos entre agosto de 2002 a marzo de 2003 en el Laboratorio de Biotecnología del Centro Nacional de Tecnología Agropecuaria y Forestal (CENTA), ubicado en el kilómetro 33 1/2 de la carretera Panamericana, cantón San Andrés, municipio de Ciudad Arce, departamento de La Libertad, El Salvador.

Esta zona se encuentra a $450 \mathrm{msnm}$, con una Latitud norte de $13^{\circ} 5^{\prime}$ y una longitud oeste de $89^{\circ} 26^{\prime}$ con valores de temperatura promedio anual de $28{ }^{\circ} \mathrm{C}$, humedad relativa de $69 \%$ y precipitación de $1.700 \mathrm{~mm}$ anuales (IGN 1970).

\section{Colecta de material vegetativo}

El material vegetativo utilizado como explante inicial fue proporcionado por plantaciones de la Finca La Flor, ubicada en la jurisdicción de Chalchuapa, departamento de Santa Ana a 700 msnm y coordenadas $13^{\circ} 59^{\prime}$ $12^{\prime \prime}$ LN y $89^{\circ} 40^{\prime} 53$ " L.W.G con una precipitación de 1.800-2.400 mm anuales. En dicha finca las plantas se registran con el mayor rendimiento.
Como explantes se utilizaron plantas en estado vegetativo, es decir, en pleno crecimiento y desarrollo; con buena apariencia y vigor, de color verduzco, sin yemas florales. Se colectaron las puntas terminales de las plantas con una longitud de $25 \mathrm{~cm}$ aproximadamente.

\section{Preparación del material vegetativo}

Una vez seleccionadas las muestras; se colocaron de cinco en cinco hojas de toallas de papel kimpak (papel utilizado para realizar pruebas de germinación) húmedas, para evitar la deshidratación para su posterior siembra.

\section{Esterilización superficial de explantes}

Para determinar el método de esterilización superficial, se realizó un ensayo previo que consistió de dos tratamientos: una combinación alcohol al 70\% durante un minuto, e hipoclorito de sodio (lejía comercial) en concentraciones de 10 y $20 \%$, durante 20 minutos respectivamente, con agitaciones periódicas. Cada tratamiento consistió de 10 repeticiones, con un meristemo en cada tubo, se efectuaron observaciones diarias durante una semana, para determinar el porcentaje de contaminación y sobrevivencia (Cuadro 1).

Cuadro 1. Daño y contaminación de los meristemos apicales del brote de loroco, inducidos a esterilización superficial con lejía comercial. Laboratorio de Biotecnología. CENTA, San Andrés, La Libertad, El Salvador. Octubre de 2002.

\begin{tabular}{lcccc}
\hline No. Tratamiento & $\begin{array}{c}\text { \% cont./ } \\
\text { hongos }\end{array}$ & $\begin{array}{c}\text { \% cont./ } \\
\text { bacteria }\end{array}$ & $\begin{array}{c}\text { Oxi- } \\
\text { dados }\end{array}$ & $\begin{array}{c}\text { Muer- } \\
\text { tos }\end{array}$ \\
\hline $\begin{array}{l}\text { 1. Alcohol 70\%+ } \\
\text { Lejía 10\% }\end{array}$ & $17 \%$ & $0 \%$ & $11 \%$ & $28 \%$ \\
$\begin{array}{l}\text { 2. Alcohol 70\%+ } \\
\text { Lejía 20\% }\end{array}$ & $0 \%$ & $0 \%$ & $11 \%$ & $78 \%$ \\
\hline
\end{tabular}

Los explantes colectados, se redujeron a $10 \mathrm{~cm}$ de largo para luego ser esterilizadas con alcohol al $70 \%$ durante un minuto y después con lejía comercial 
al 10\% durante 20 minutos agitando periódicamente; seguidamente se realizaron cuatro enjuagues con agua destilada esterilizada, los explantes se mantuvieron en agua destilada esterilizada para evitar la deshidratación antes de ser seccionadas.

\section{Siembra de meristemos}

Los meristemos fueron extraídos con ayuda de un estereoscopio y pinzas, para separar las brácteas de la yema apical y dejar libre al meristemo para su extracción; luego se procedió a sembrar un meristemo de aproximadamente $0,1-0,2 \mathrm{~mm}$ por tubo de ensayo de 150 x $25 \mathrm{~mm}$ que contenía $10 \mathrm{ml}$ de medio de cultivo, sellado con plastic wrap y se identificaron según el tratamiento y su respectiva concentración; dichos medios constaron de un Murashige y Skoog (1962) basal suplementado con vitaminas: tiamina $0,1 \mathrm{mg} / \mathrm{l}$, ácido nicotínico $0,5 \mathrm{mg} / \mathrm{l}$, piridoxina $0,5 \mathrm{mg} / \mathrm{l}$; inositol 100 $\mathrm{mg} / \mathrm{l}$, sacarosa $30 \mathrm{mg} / \mathrm{l}$, glicina $0,1 \mathrm{mg} / \mathrm{l}$ y diferentes concentraciones de reguladores de crecimiento: bencilaminopurina (BAP) y ácido naftalenacético (ANA ) que se muestran en el Cuadro 2.

Los nueve tratamientos fueron ajustados a un $\mathrm{pH}$ : 5,7 , gelificados con phytagel y esterilizados en autoclave

Cuadro 2. Distribución de las combinaciones de las concentraciones de BAP y ANA por tratamiento. CENTA, El Salvador. 2002.

\begin{tabular}{|c|c|c|c|}
\hline BAP/ANA & 0,0 mg / & $0,5 \mathrm{mg} / \mathrm{l}$ & $1,0 \mathrm{mg} / \mathrm{l}$ \\
\hline 0,0 mg/l & $\begin{array}{c}0,0 \mathrm{mg} / \mathrm{l}+ \\
0,0 \mathrm{mg} / \mathrm{l} \\
(\mathrm{M} 1)^{*}\end{array}$ & $\begin{array}{c}0,0 \mathrm{mg} / \mathrm{l}+ \\
0,5 \mathrm{mg} / \mathrm{l} \\
(\mathrm{M} 2)\end{array}$ & $\begin{array}{c}0,0 \mathrm{mg} / 1+ \\
1,0 \mathrm{mg} / 1 \\
(\mathrm{M} 3)\end{array}$ \\
\hline 0,5 mg/l & $\begin{array}{c}0,5 \mathrm{mg} / \mathrm{l}+ \\
0,0 \mathrm{mg} / \mathrm{l} \\
(\mathrm{M} 4)\end{array}$ & $\begin{array}{c}0,5 \mathrm{mg} / \mathrm{l}+ \\
0,5 \mathrm{mg} / \mathrm{l} \\
\text { (M5) }\end{array}$ & $\begin{array}{c}0,5 \mathrm{mg} / 1+ \\
1,0 \mathrm{mg} / 1 \\
(\mathrm{M} 6)\end{array}$ \\
\hline $1,0 \mathrm{mg} / \mathrm{l}$ & $\begin{array}{c}1,0 \mathrm{mg} / \mathrm{l}+ \\
0,0 \mathrm{mg} / \mathrm{l} \\
(\mathrm{M} 7)\end{array}$ & $\begin{array}{c}1,0 \mathrm{mg} / \mathrm{l}+ \\
0,5 \mathrm{mg} / \mathrm{l} \\
(\mathrm{M} 8)\end{array}$ & $\begin{array}{c}1,0 \mathrm{mg} / \mathrm{l}+ \\
1,0 \mathrm{mg} / \mathrm{l} \\
\text { (M9) }\end{array}$ \\
\hline
\end{tabular}

$* \mathrm{M}=$ tratamientos.

$\mathrm{BAP}=$ Ácido Bencilaminopurina. ANA = Ácido Naftalenacético. a una presión de $15 \mathrm{lb} / \mathrm{Pul}^{2}$ y a una temperatura de $121^{\circ} \mathrm{C}$ durante 20 minutos. Cada medio contó con 10 repeticiones cada uno con 90 repeticiones (M1 fue el tratamiento control). Luego, las yemas se sometieron a un periodo de desarrollo en dos fases: iniciación y multiplicación.

\section{Fases experimentales}

La metodología de trabajo abarcó una fase de campo, posterior a esta, una de laboratorio, de la cual se obtuvieron los resultados de los efectos de los reguladores de crecimiento en los meristemos sembrados, estos pasaron a la deshidratación de callos para la regeneración de plántulas a través de estos, y pruebas de enraizamiento de plántulas de loroco, obtenidas en la fase de iniciación, posteriormente pasaron a una fase de multiplicación.

En la etapa de iniciación o establecimiento se indujo el crecimiento de brotes generados del cultivo de meristemos, sembrados en cada uno de los tratamientos descritos anteriormente. El periodo de duración de esta fase fue de cuatro semanas.

En la etapa de multiplicación o micropropagación, se cortaron los segmentos más pequeños las plántulas obtenidas en la fase de iniciación, se cambiaron a medios frescos cada 28 días, durante 12 semanas.

En la fase de multiplicación de callos, se tomaron pequeñas cantidades de callos formados y sembrados en frascos de vidrio, con un volumen de $225 \mathrm{ml}$, según la composición del tratamiento. Fueron dispersados en la superficie del medio de cultivo para propiciar su crecimiento. La duración del ensayo de formación de callos fue de 12 semanas.

\section{Parámetros de evaluación}

Se evaluaron variables cualitativas y cuantitativas para cada fase; en la fase de iniciación se evaluó porcentaje de sobrevivencia de los meristemos, días a formación de callos y días a brotación. En la fase de 
multiplicación se evaluó: número de brotes por explante, y la textura del callo (friable o compacto).

\section{Pruebas experimentales alternas}

La deshidratación de callos consistió en colocar en cajas petri esterilizadas con un disco de papel filtro en su interior, se dispersaron de cuatro a cinco callos por caja provenientes de los diferentes tratamientos que produjeron callos de mejor apariencia y textura, para someterlos a estrés hídrico durante 6, 12 y 24 horas, colocados bajo oscuridad total en los tiempos respectivos.

La regeneración de plántulas consistió en colocar en medios de regeneración, los callos sometidos a estrés hídrico, en medios de Murashige y Skoog suplementados con concentraciones de 0,$5 ; 1,0 ;$ y 1,5 $\mathrm{mg} / \mathrm{lde}$ BAP (bencilaminopurina) y se colocaron inmediatamente a la luz para propiciar brotación de hojas, tallos o raíces.

\section{Diseño estadístico}

Fue un factorial $3^{2}$ completamente aleatorizado con 10 observaciones para cada tratamiento. Los resultados obtenidos fueron analizados por medio del análisis de varianza con igual número de repeticiones, con un nivel de significancia del 0,5\%.

\section{RESULTADOS Y DISCUSIÓN}

A los 60 días se alcanzó el mayor número de formaciones de éstos, lo que comprueba que el estado fisiológico de la planta que dona el explante influye significativamente en su capacidad morfogénica, pues entre más joven y menos diferenciado esté el tejido que se va a sembrar, mejor será la respuesta in vitro (CIAT 1991). Esto se comprobó con la siembra de meristemos apicales en estado vegetativo activo al regenerar plántulas más rápidamente. Por lo que se logró la formación de brotes in vitro de loroco a los quince días, así mismo se debe recordar que el tipo de morfogénesis que ocurre en un cultivo depende de la proporción y concentración de auxinas y citocininas presentes en el medio (Kenneth 1989) (Cuadro 3). Ante esto, es preciso destacar el papel determinante que juegan los reguladores de crecimiento en las respuestas in vitro de los diferentes tipos de explantes.

Cuadro 3. Evaluación del efecto de los reguladores de crecimiento en los explantes de loroco (Fernaldia pandurata Woodson). Laboratorio de Biotecnología, CENTA. San Andrés, La Libertad, El Salvador. Agosto 2002-marzo 2003.

\begin{tabular}{lcc}
\hline Tratamientos & $\begin{array}{c}\text { Formación } \\
\text { de callos }\end{array}$ & $\begin{array}{c}\text { Formación } \\
\text { de brotes }\end{array}$ \\
\hline 1: $0,0 \mathrm{mg} / 1 \mathrm{BAP}+0,0 \mathrm{mg} / 1 \mathrm{ANA}$ & $\mathrm{No}$ & $\mathrm{No}$ \\
2: $0,0 \mathrm{mg} / 1 \mathrm{BAP}+0,5 \mathrm{mg} / 1 \mathrm{ANA}$ & $\mathrm{Si}$ & \\
3: $0,0 \mathrm{mg} / 1 \mathrm{BAP}+1,0 \mathrm{mg} / 1 \mathrm{ANA}$ & $\mathrm{Si}$ & $\mathrm{Si}$ \\
4: $0,5 \mathrm{mg} / 1 \mathrm{BAP}+0,0 \mathrm{mg} / 1 \mathrm{ANA}$ & $\mathrm{Si}$ & \\
5: $0,5 \mathrm{mg} / 1 \mathrm{BAP}+0,5 \mathrm{mg} / 1 \mathrm{ANA}$ & $\mathrm{Si}$ & \\
6: $0,5 \mathrm{mg} / 1 \mathrm{BAP}+1,0 \mathrm{mg} / 1 \mathrm{ANA}$ & $\mathrm{Si}$ & $\mathrm{Si}$ \\
7: $1,0 \mathrm{mg} / 1 \mathrm{BAP}+0,0 \mathrm{mg} / 1 \mathrm{ANA}$ & & \\
8: $1,0 \mathrm{mg} / 1 \mathrm{BAP}+0,5 \mathrm{mg} / 1 \mathrm{ANA}$ & $\mathrm{Si}$ & \\
9: $1,0 \mathrm{mg} / 1 \mathrm{BAP}+1,0 \mathrm{mg} / 1 \mathrm{ANA}$ & $\mathrm{Si}$ & \\
\hline Total & 7 & 2 \\
\hline
\end{tabular}

Los reguladores de crecimiento que el cultivo de meristemos requiere, dependen de la especie de la planta y fase del cultivo. Diferentes familias de plantas requieren altas o bajas concentraciones de hormonas de crecimiento exógenas. En algunas especies, durante la fase de iniciación, no requieren el uso de reguladores de crecimiento externos; la mayoría de especies requieren bajos niveles de citoquininas para el crecimineto y desarrollo de meristemos; sin embargo, altos niveles de citoquininas pueden promover la proliferación de brotes axilares, mientras que altas concentraciones de auxinas pueden promover la formación de callos (Vasil y Torpe 1994).

Los tratamientos 4 y 7 fueron los medios que presentaron un exitoso crecimiento de brotes generados a partir del cultivo de meristemos (Figura 2); esto concuerda con (1991), el cual afirma que el BAP (ácido bencilaminopurina) promueve una alta proliferación meristemática y se utiliza en concentraciones entre 0,1 a 1,0 mg/l para la formación de brotes. Así mismo, esto concuerda con pruebas realizadas por López 

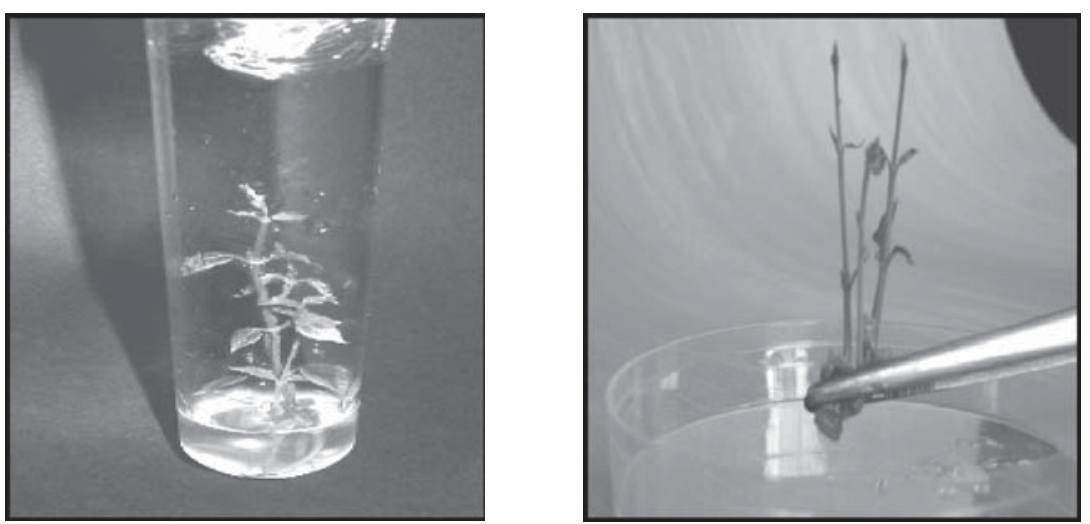

Figura 2. Obtención de plántulas de loroco (Fernaldia pandurata Woodson) en medio de cultivo MS basal suplementado con $0,5 \mathrm{mg} / 1$ de BAP Y $1,0 \mathrm{mg} / 1$ de BAP respectivamente. Laboratorio de Biotecnología. CENTA, San Andrés, La Libertad, El Salvador. Octubre de 2002.

(1997) en el cultivo in vitro de loroco a partir de semillas, donde obtuvo plántulas en medios de cultivo MS basal suplementados con $0,5 \mathrm{mg} / \mathrm{l}$ de BAP.

Los resultados obtenidos en el análisis de varianza, muestran que existen diferencias significativas en cuanto a la regeneración de brotes, siendo la concentración de 1,0 mg /l BAP el más eficiente en promover una mejor elongación y cantidad de tallos obtenidos.

Los tratamientos donde los medios de cultivo estuvieron suplementados solo con auxinas o combinadas con proporciones altas y bajas de citoquininas como reguladores de crecimiento, produjeron callos friables. Se determinó que existe diferencia significativa entre los tratamientos que presentaron como efecto la formación de callos, ya que variaron en cuanto a la cantidad de callo que cada uno formó (Cuadro 4), lo que puede atribuirse al efecto de las auxinas en la estimulación de la división celular, que en forma combinada con las citocininas (BAP), promueven la disociación de tejidos en grupos celulares (Figura 3 ).

Actualmente no existe mayor información acerca de la propagación in vitro de loroco con base en meristemos apicales del brote de este cultivo, así como de su
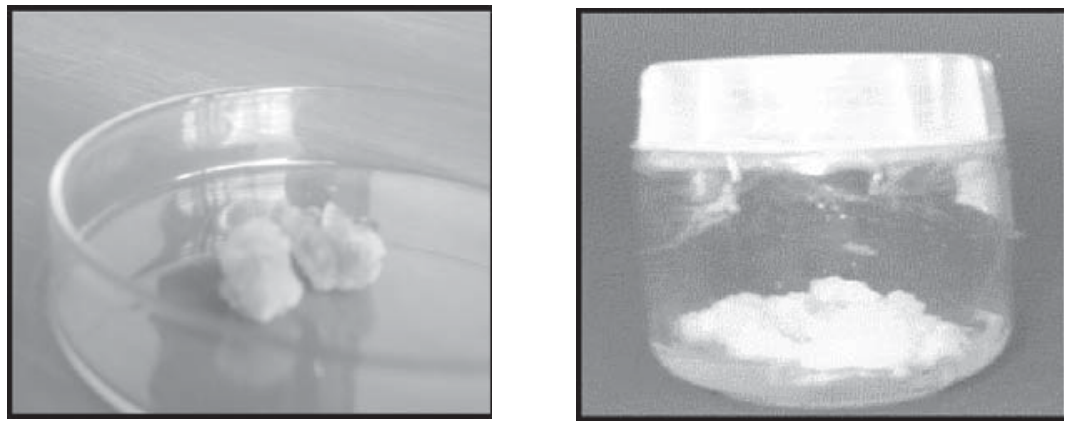

Figura 3. Callos formados en medio de cultivo MS basal suplementados solo con auxinas o combinadas con citocininas. CENTA, San Andrés, La Libertad, El Salvador. Octubre de 2002. 
Cuadro 4. Textura de los callos formados en cada tratamiento en cuanto al efecto de las auxinas en los explantes de loroco (Fernaldia pandurata Woodson). Laboratorio de Biotecnología. CENTA. San Andrés, La Libertad, El Salvador. Agosto 2002-marzo 2003.

\begin{tabular}{ccc}
\hline Tratamientos & \multicolumn{2}{c}{ Formación de callos } \\
\cline { 2 - 3 } & Friable & Nodular \\
\hline 2: $0,0 \mathrm{mg} / 1 \mathrm{BAP}+0,5 \mathrm{mg} / \mathrm{l} \mathrm{ANA}$ & $\mathrm{Si}$ & \\
3: $0,0 \mathrm{mg} / \mathrm{l} \mathrm{BAP}+1,0 \mathrm{mg} / \mathrm{l} \mathrm{ANA}$ & $\mathrm{Si}$ & \\
4: $0,5 \mathrm{mg} / 1 \mathrm{BAP}+0,0 \mathrm{mg} / \mathrm{ANA}$ & $\mathrm{Si}$ & $\mathrm{Si}$ \\
5: $0,5 \mathrm{mg} / \mathrm{BAP}+0,5 \mathrm{mg} / \mathrm{ANA}$ & $\mathrm{Si}$ & $\mathrm{Si}$ \\
6: $0,5 \mathrm{mg} / 1 \mathrm{BAP}+1,0 \mathrm{mg} / \mathrm{ANA}$ & $\mathrm{Si}$ & $\mathrm{Si}$ \\
8: $1,0 \mathrm{mg} / \mathrm{BAP}+0,5 \mathrm{mg} / \mathrm{ANA}$ & $\mathrm{Si}$ & \\
9: $1,0 \mathrm{mg} / \mathrm{l} \mathrm{BAP}+1,0 \mathrm{mg} / \mathrm{l} \mathrm{ANA}$ & $\mathrm{Si}$ & $\mathrm{Si}$ \\
Total & 7 & 4 \\
\hline
\end{tabular}

caracterización morfológica y molecular. Se estima la existencia de cinco a ocho variedades criollas, por lo que es de vital importancia impulsar una nueva técnica de producir y mejorar la calidad de este cultivo, siendo esta a través de la micropropagación, garantizando así, satisfacer la demanda del producto, ya que el loroco ha ingresado a formar parte del grupo de productos de exportación de El Salvador.

En cuanto a la deshidratación y regeneración de callos, no se lograron obtener plántulas, pues se perdieron los explantes. Algunos explantes se necrosaron, y a causa de ello, no se observó regeneración de ningún tipo de estructuras; esto puede deberse a la cantidad y calidad de nutrientes que contenía el medio. Taiz y Zeiger (1991) explican que cuando los callos de algunas especies son cultivadas repetidamente por un periodo de tiempo, los tejidos pierden su capacidad morfogénica. A un inicio, se observó que los callos presentaban actividad fotosintética en su periferia, luego tomaron una coloración pálida que normalmente presentan.

El cultivo de meristemo es una técnica que requiere una escisión aséptica de la región meristemática del brote. Se establece bajo condiciones asépticas del medio de crecimiento y la subsecuente manipulación del crecimiento con base en la adición de hormonas, además de ciertas condiciones propias del cultivo, para la obtención de plántulas completas (Vasil y Torpe 1994).

\section{CONCLUSIONES}

Fue posible propagar loroco (F. pandurata Woodson) por medio de la técnica de cultivo in vitro de tejidos vegetales utilizando los meristemos apicales del brote como explantes.

Existió diferencia significativa en los diferentes tratamientos evaluados en cuanto a la formación de callos y brotes.

El tratamiento compuesto por MS basal + BAP $1,0 \mathrm{mg} / \mathrm{l}$ fue el más eficiente en la obtención de brotes ya que fue el que indujo mayor porcentaje de explantes con formación de estos.

La adición de citocininas (BAP) al medio de cultivo, se logró la formación de brotes in vitro de loroco a los 15 días.

La presencia de auxinas y citoquininas en el medio de cultivo, es indispensable para la inducción de callo y formación de brotes, ya que al no agregarlos, los meristemos no muestran respuesta alguna para la formación de éstos.

Los meristemos apicales fueron los explantes más efectivos para la producción de plantas completas y sanas de loroco.

\section{RECOMENDACIONES}

Realizar investigaciones enfocadas en la optimización de las concentraciones adecuadas de auxinas y citoquininas para la formación de plántulas vía callogénesis.

Utilizar del medio MS basal suplementado con $1,0 \mathrm{mg} / \mathrm{l}$ de BAP, para propagar de manera rápida y eficaz el loroco in vitro, a través de la técnica de cultivo de meristemos en medio sólido. 


\section{LITERATURA CITADA}

ARGUETA, J. 1989. Cultivo de loroco tiene alto valor comercial y nutritivo. Sección agropecuaria. San Salvador, El Salvador. Prensa gráfica. Oct.31:39.

CALDERON.S Y STANDLEY.1941. Lista preliminar de la flora salvadoreña. Imprenta Nacional, San Salvador, El Salvador, C.A.

CENTA (Centro Nacional de Tecnología Agropecuaria y Forestal). s. a. Cultivo del "Loroco". Boletín Informativo. 8 p.

CIAT (Centro Internacional de Agricultura Tropical) 1991. In: Roca, W; Mrogginski, L. eds. Cultivo de tejidos en la agricultura: Fundamentos y aplicaciones. Cali, Colombia. Px ii, 970.

DAMAS, M. 1984. Cultivo de loroco (Fernaldia pandurata Woodson). Escuela Nacional de Agricultura "Roberto Quiñónez". Departamento de fitotecnia, Unidad de horticultura, sub-unidad de hortalizas. $4 \mathrm{p}$.

ESPINOZA.N; R.ESTRADA; P.TOVAR.1985. Cultivo de Tejidos: Micropropagación, conservación y exportación de germoplasma de papa. Centro Internacional de la Papa (C.I.P). Lima, Perú. 17 p. (Documento de tecnología especializada 1$)$.

FAO (Organización Naciones Unidas para la Agricultura y la Alimentación), 1995. Biotecnología apropiable: Racionalidad de su desarrollo y aplicación en América Latina y El Caribe. Red de cooperación técnica en biotecnología vegetal. Santiago de Chile. 81 p.

FLORES, J., 1978. Cultivo y algunos datos etnobotánicos del "loroco"(Fernaldia pandurata Woodson). San Salvador. Departamento de Biología. Facultad de Ciencias y Humanidades. Universidad de El Salvador. Comunicaciones, Vol. II.

HURTADO.D.; MERINO, M. 1987. Cultivo de tejidos vegetales. Editorial Trillas, S.A. de C.V. México, D.F. $232 \mathrm{p}$.

IGN (Instituto Geográfico Nacional.) “ING. Pablo Guzmán”. 1970. Diccionario Geográfico de El Salvador, Tomo II.
Talleres litográficos del Instituto Geográfico Nacional. Ministerio de Obras Públicas de El Salvador. 337 p.

ISTA (Instituto Salvadoreño de Transformación Agraria). 1985. Guía técnica de hortalizas. División de desarrollo empresarial. Departamento de producción agropecuaria. $10 \mathrm{p}$.

KENNETH, C. 1989. Tissue culture techniques for horticultural crops. Van Nostrand Runhold (AVI Book) New Cork, United States of America. 285 p.

KUAN, CH; OSPINA, I. 1990. Introducción a la técnica de cultivos vegetales. Instituto Nacional de Aprendizaje, Departamento técnico agropecuario, sección de fitotecnia. Granja modelo. Misión tecnica agrícola de la República China. San José, Costa Rica. 86 p.

LÓPEZ, C.1990. Fundamentos teórico-practico del cultivo de tejidos vegetales: Establecimiento de un laboratorio de cultivo de tejidos. Organización de las Naciones Unidas para la Agricultura y la Alimentación. Estudio FAO producción y protección vegetal. Roma, Italia. p. 9-13.

LÓPEZ, Y.E. 1997. Cultivo in vitro de loroco (Fernaldia pandurata Woodson) a partir de semillas. Escuela de Biología, Facultad de Ciencias Naturales y Matemática, Universidad de El Salvador. San Salvador, El Salvador. 4 p. (boletín divulgativo)

NARENDER, S.; KUTTY, K. 1994. Plant cell and tissue culture. In: Vasil, I y Thorpe, T eds. Meristem and shoot tip culture. Klewer Academic Publishers. The Netherlands. 593 p.

NAVARRO, D. 1992. Estudio técnico económico de las prácticas económicas en el cultivo de loroco y su efecto en el rendimiento en los departamentos de Sonsonete y San Salvador. Facultad de ingeniería y agricultura. Universidad de El Salvador. San Salvador, El Salvador (Tesis de Ingeniero agrónomo). 99 p.

ORELLANA, J. 1987. El loroco en El Salvador. Boletín técnico No.1-8. Departamento de Comunicaciones de la región II. Ministerio de Agricultura y Ganadería.

OSORIO, E.1994. Cultivo del "loroco". Boletín Informativo. 8 p.

AGRONOMÍA MESOAMERICANA 18(1): 75-84. 2007 
OSORIO, E.; PARADA, M.; ESCAMILLA, E.; QUINTANILLA, R. 2002. Cultivo de loroco. Guía Técnica No. 9 Centro Nacional de Tecnología Agropecuaria y Forestal. División de Investigación Agrícola. Programa de Hortalizas. San Andrés, La Libertad, El Salvador. 48 p.

QUINTANILLA,M, K. 2003. Micropropagacion in vitro de loroco (Fernaldia pandurata Woodson) a partir de meristemos apicales del brote. Escuela de Biología, Facultad de Ciencias Naturales y Matemática, Universidad de El Salvador (Tesis de Licenciatura). 89 p.
RIVERA.M. 2001. "El loroco", el cultivo de moda. Consultado 27 oct. 2001. Disponible en http:www.elsalvador. com/hablemos/ediciones/150701/forraje.

TAIZ, L; ZEIGER, E. 1991. Plant physiology. The Benjamin/cummings Publishing Company, Inc. United States of America. 559 p.

VASIL, I.; TORPE, T. 1994. Plant Cell And Tissue Culture. Klumer Academic Publisher The Netherlands. 587 p. 